\title{
Interactive comment on "Effect of Atmospheric Stability on the Wind Resource extrapolating models for large capacity Wind Turbines: A Comparative Analysis of Power Law, Log Law and Deaves and Harris mode" by Pramod Kumar Sharma et al.
}

Pramod Kumar Sharma et al.

sharma786pramod@gmail.com

Received and published: 17 May 2018

Dear Sir Thanks for your valuable feedback

As per the comments are given by the referees in the form of supplement, the following major revisions have been made: 1 . All marked sentences are rephrased and corrected. 2. Quality of all figures has been enhanced and discussed in the literature. 3. Wherever the mistake of English was mentioned, it had been corrected accordingly. 
5. Meaningless sentences have been omitted from the literature. 6. All other minor remarks have been incorporated.

WESD

Please see the revised file.

Please also note the supplement to this comment:

https://www.wind-energ-sci-discuss.net/wes-2018-16/wes-2018-16-AC2-

Interactive

comment

supplement.pdf

Interactive comment on Wind Energ. Sci. Discuss., https://doi.org/10.5194/wes-2018-16, 2018. 